Virtual Creativity

Volume 11 Number 1

(c) 2021 Intellect Ltd Article. English language. https://doi.org/10.1386/vcr_00042_1

Received 16 December 2020; Accepted 23 February 2021

MATTHEW SANSOM

Sunway University

ZI SIANG SEE

University of Newcastle, NSW

\title{
Translating performative mediated art into virtual reality: A case study
}

\begin{abstract}
Park benches are distinctive public spaces that invite a temporary pause for thought and time out from everyday activities and worldly preoccupations. Park Bench Sojourn is a multimodal arts project that explores the uniqueness and universality of these spaces and the kinds of experiences they foster. It asks what it means to be human; surrounded, as we are, by computer technologies and digital media, living lives that are perpetually 'connected' and dispersed through the cloud. It reflects on how our technologically determined lives and lifestyles conspire against us to find opportunities to stop, reflect and be witnesses to lived experience. It is a conceptually playful creative work that shares concerns for health and well-being arising from the contemporary mindfulness movement and the traditional practices and worldviews upon which mindfulness draws. The project is based around a range of experiential sojourns, which require participants to find a bench to sit on and then take a sojourn, or a number of sojourns from the project's website, which may include audio, video, spoken word, or just listening. Other iterations of the project have included a multimedia gallery installation juxtaposing content from a variety of sojourns. Regardless of the format, context or specific content, the project explores ways in which we 'perform' ourselves and mediate experience via digital technologies. In this article, we describe the process of translating this mediated and performative artwork into a VR prototype and directions for future work.
\end{abstract}

\section{KEYWORDS}

practice-based research technological mediation virtual reality assistive technology interdisciplinarity interaction design interactive media 


\section{INTRODUCTION}

Park Bench Sojourn (PBS) is built around the activity of taking some time out or a sojourn (i.e. a temporary visit) on a bench. Sojourns include the process of walking to and from the bench. The website parkbenchsojourn.org, home to the project, states that:

Park bench sojourns are experiential and require participants to find a bench to sit on for the purposes of the sojourn. [...] You are invited to participate in the project through the selection of sojourns available, any number and type, as appropriate, per outing.

(Sansom 2020)

The sojourns themselves vary in nature, with each one emphasizing a particular sense and kind of experience. For example, 'audio sojourns' comprise listening to audio recordings made from other benches, while 'sight sojourns' require you to watch video recordings that silently replay views from other benches. Choosing a 'voice sojourn' allows you to listen to a disembodied narrator describing what they see, hear and experience from yet another bench. The various kinds of content are all available via mobile phone through downloading or streaming. Other iterations of the project, currently there are nine variants, have included a multimedia gallery installation juxtaposing content from a variety of sojourns, geographically located audio versions using a mobile app and a VR version - the topic of this article.

\section{RESEARCH METHODOLOGY}

The initial idea for PBS arose in 2011 from Matthew Sansom's practice as a phonographer and sound artist. Looking for ways to present audio recordings that included a contextual and conceptual element, the idea was to curate audio recordings made from park benches. After its initial ideation, PBS was to remain just an idea until only after the ecological-arts research project Landscape Quartet (LQ) occurring between 2012 and 2015 (Hogg 2020). Nevertheless, during that period, LQ shaped the development of PBS in important ways.

Funded by the UK Arts and Humanities Research Council, LQ, also practice-based, explored the creative and theoretical possibilities of working artistically in direct dialogue with the environment, and resulted in a wide range of creative works including installations and performances (in galleries and in the environment itself, including, for example, a Vietnamese rice field and a Swedish forest), as well as audio-visual works, seminars and journal articles.

Informed by recent environmental and eco-critical thinking its remit was to explore the creative and theoretical possibilities afforded by working in direct dialogue with the environment. It was a critique of conventional postEnlightenment mechanisms of representation, which, as Bennett Hogg the project's PI puts it, serve to perpetuate the ideological blind othering of 'nature' (Hogg 2013). Advocating philosophical positions that argue for the 'interconnectivity of things' it explored sonic and musical arts practices that were participative and eco-systemic in approach. Integral to this was a relational epistemological emphasis, which focused on modes of knowledge accessible to us as involved participants, situated performers working in and through the habitat; and where insights into this relationship then presented themselves 
through artistic expression, with its particular qualities as a 'communicator of knowledge' (Borgdorff 2010).

Non-Representational Theory (as developed by cultural geographer Nigel Thrift) and also the work of Tim Ingold brought further refinement to this methodology. Non-representational theory, as a counter to reductivism and the privileging of the visual, foregrounds all the senses, embodiment, performances and practices; it views the world in practical and processual terms as something in a perpetual state of becoming (Waterton 2012: 68). Similarly, Ingold's 'dwelling perspective', proposes that through immersion in the inescapable condition of existence, the world continually comes into being around us (Ingold 2000: 153); and by what he terms wayfinding we move and 'feel our way' through a world, a world (or lifeworld) that itself is continually coming into being (Ingold 2000: 155). On this basis, the LQ sought to act from, acknowledge and communicate proximity with and interconnectedness between each other and the environments we worked in. Furthermore, we aimed for the multisensory fusion of being and doing, binding feelings of place and self across a variety of registers - including not only sound, but also, memory, physicality, encounters with animals and vegetation, imagination, smell and sight, pre-cognitive and pre-conscious intuitions, and so on.

A tension within the Quartet's approach, that PBS is, in part, a response to, was a cautiousness towards field recording; a cautiousness due to its historic associations with objectification through documentation on the one hand, and the fetishization of the captured sound-object on the other. Although a simplification, it is a useful shorthand to understand how such practices and their philosophical roots serve in the objectification of experience towards a nonparticipative distancing, at odds with the explicit aims of the Quartet. PBS, however, speaks to this simplification and offers some critique of the Quartet's characterization of participation.

PBS is arguably more transparent in its commitment to LQ's methodological and theoretical basis by more directly incorporating our existential status as 'lifeworld participants'. It is concerned with less directly interventionist modes of participation and turns more explicitly towards activities such as walking, stillness, watching, listening, feeling, reflecting, as well as the possibility for making audio field-recordings (and other forms of reflective and mediated documentation) within this. It is interesting to note that equivalent phases of relative 'inactivity', what members described as 'attunement' and 'tuning-in' (Vogel 2015), were indispensable to the Quartet's approach as the precursor to any further work. As such, PBS locates its practice in the accessible and universal qualities of experience that proved conditional for the kinds of active participation explored by the Quartet: kinds of practice or performativity that, by virtue of their embodied immediacy and subtly inherent reflexivity, are arguably just as participative. PBS' interest is not to recover and affirm the connections we share through overtly participative activities, but rather to facilitate a more nuanced and essentialist mode of contemplative witnessing that affords access to the relational and unitive qualities of experience, our dwelling as part of, and participants with, nature and the lifeworld as it unfolds around us.

\section{MULTIMODALITY AND PARTICIPATION}

As well as the Quartet's efforts to explore proximity with and interconnectedness between each other and the environment, the multimodal scope of the 
project extended this to include the spaces, places and resources lying beyond initial locations (from rural environment to gallery, concert venue, fixed media compositions, video works and so on).

In order to interpret and understand how subsequent artefacts connected, and still connect, with the project's participative agenda it was argued that subsequent works are born of and exist in ongoing relational processes (Sansom 2015). Cultural geographer David Crouch makes the argument that such representations, themselves born of the performativity of living, are in no sense fixed or closed to change but rather 'remain open too, "available" for further work' (Crouch 2012). This, along with Barbara Bolt's view of art's performative potential as a dynamic material exchange, rather than merely a signifying representational act (Bolt 2010: 8), helped position the Quartet's 'after-the-event' artefacts as reconfigurations of the constitutive and constituting relations of performative participation; a dynamic that reaches back to the 'original' explorations as well as forwards to the cycle of subsequent artefacts.

In spite of this (and of the idea that 'Landscape Quarteting' might become its own arts-practice that people would do, just as they might walk their dog or do some gardening) the ideal of participation for those encountering our work presented a challenge. Participative engagement remained necessarily wedded to the performativity of the Quartet, with the audience rather conventionally distanced and outside processes of participation. The epistemological potential of participation, where, to quote Brian Haseman, 'the knower and the known interact, shape and interpret the other' had limited reach beyond our own, admittedly rich, experiences (Haseman 2006, 2010).

PBS, although in many ways an extension of the Quartet's vision, addresses this by disabling conventional roles and enabling a range of experiential possibilities, in part facilitated by its adoption of ubiquitous mediating technologies. Its reciprocal simplicity and quotidian directive allow for a levelling out of agency and aesthetic experience, breaking the distinction between my own activities and those of any other sojourner. The performativity of PBS is shaped and experienced through a range of activities and roles, and their combinations: it can remain a concept; be a provocation to act; an act of recording, a narration of one's experience, and its sharing; it can be several types and any number of sojourns across various times and places; and the combination of sojournic content, the walk and its bench is distinctly unique to the individual. It offers an accessible encounter between knower and known, an equitable and embodied approach that affirms the non-specialist reality of existence and human experience. It flattens out the politics of listening and traditionally defined arts-related subject positions. PBS is distributed through a range of possible kinds of experience, aesthetic encounter, media and participative engagement: interpretative and relational epistemology shapes both content and form.

\section{‘LOSS OF SELF’ AND AESTHETIC EXPERIENCE}

A consistent focus in Sansom's work, as an artist and academic, has been experiences where objectively perceived states of consciousness fluctuate and give way to a 'loss of self'. For the Quartet this was a characteristic quality of both the preparatory (the initial stages of 'tuning-in') and more conventional performative stages.

Similar experiences in musical free improvisation are well-documented. David Borgo, for example, recounts musicians' descriptions of ecstatic and 
trancelike states, the annihilation of critical and rational faculties, and quotes the bassist William Parker's explanation of free music as an 'emptying [of] oneself and being' (Borgo 2005: 325). Similarly, Stephen Nachmanovitch, describing it as a'common experience', writes:

The intensity of your focused concentration and involvement maintains and augments itself, your physical needs decrease, your gaze narrows, your sense of time stops. You feel alert and alive; effort becomes effortless $[\ldots]$ you forget time and place and who you are. The noun of self becomes a verb.

(Nachmanovitch 1990: 51-52)

Drawing other conclusions, in the area of music education and spirituality, a number of musicologists and educationalists also describe similar qualities of experience. Deanne Bogdan, for example, describes what she calls the'shivershimmer' factor of aesthetic experience, which she broadly defines, with reference to Dewey, as 'dissolving sharp distinctions among aesthetic, religious, spiritual, and learning experience at its most salutary [...] akin to the mysti$\mathrm{cal} /$ religious attitude of holding oneself open, the collapse of ego boundaries, and a sense of oneness with "what is"' (Bogden 2010: 118). Rhoda Bernard brings together Maslow's concept of self-actualizing 'peak experiences' with Csikszentmihalyi's evolutionist understanding of 'flow experiences' to 'illuminate the parallels between transcendent music making experiences and transcendent religious experiences' (Bernard 2009: 10).

More recently, Sansom has offered some critique of this body of work and its mainstay opinion that makes a too direct comparison between spirituality and such kinds of aesthetic encounter: June Boyce-Tillman, for example, goes so far as to state, 'the aesthetic is a secular term for the Spiritual domain' (Boyce-Tillman 2007: 1418). Here, Sansom has explored parallels with ideas drawn from the Traditionalist School in the writings of René Guénon and Ananda Coomaraswamy (Sansom 2017). The Traditionalist School holds to an absolutist view of a single perennial or primordial revealed truth that, across time and culture, has taken on other forms (whether in Buddhism, Plato, Hinduism, Native American Indians, Islam, Zoroastrianism and so on). It is of special significance due to its particular emphasis on the relevance of selfhood and its dissolution, and the context and meaning of such experiences. From a traditionalist metaphysical context, the 'loss of self' is elevated to the profoundest of spiritual and metaphysical truths: that the seemingly concrete reality of one's perception and sense of individual consciousness is wholly contingent on something Other and far greater, the Supreme Absolute or, in Aldous Huxley's words, the 'spiritual Ground of all things' (Nelson 2009: 122). Furthermore, full knowledge of this is attainable through the right kind of sustained 'inner work', and is a category of knowledge that is (a) transformative, replacing the self-regarding ego with a permanent realization of the Supreme Identity, and (b) accessible through supra-mental intuition, rather than the ratio-centric intellect (Rooth 2008: 140). Arguably, a more accurate comparison with transcendent-like aesthetic experience, is that it is related to, but distinct from, such a notion of spirituality and its concomitant experiences (Sansom 2017). One is understood as transcendent and permanently altering of consciousness, the other as temporary and psychologically rooted: one, is directly participative in metaphysical Reality; the other, a symbolic mirroring, a sign and reminder of that same Reality. This comparison is rooted in a core 
metaphysical tenet of the Perennial Philosophy of the Traditionalist School, described, by the eminent thirteenth-century Islamic scholar and mystic Ibn'Arabi, as the 'Unity of Being'. Ibn'Arabi explains that we are able to view the Absolute Reality of Being, from which all things emanate, from two different angles: (1) as the Essence of all phenomena and (2) as the manifested phenomena of that Essence. Reality and appearance, the One and the many: two subjective aspects of One Reality, transcending all forms and whatever characteristics belong to them (Affifi 1998: 11). Significantly, only a person possessed of the vision of a mystic can transcend, in a supra-mental state of intuition, the multiplicity of forms in order to 'see' the Reality that underlies them, to grasp the Whole as a Whole (Affifi 1998: 12).

\section{TECHNOLOGICAL MEDIATIONS OF THE METAPHYSICAL: PBS VR PROTOTYPE}

Naturally enough, PBS shares a connection with these ideas, particularly so in relation to the project's aesthetic and conceptual basis. PBS offers a methodology and approach which, at the least, acknowledges and affirms alternate categories of knowledge and modes of being. Growing from its roots in practice-based research and environmental arts practice towards, as has been argued, more open and accessible ways of knowing our presence within, and as part of, the lifeworld, it emphasizes embodied, procedural and intuitive modes of understanding. This extends to include the idea that metaphysical insights might also reflect and refract through the work and its experience. Park benches as metaphor and idea are universally ubiquitous; in the practice of 'life-performed' park bench encounters are singularly experiential and unique. Using the mobile phone as a mediating focal point, park bench sojourns engender both aspects (unity and multiplicity) across both form and content. Park bench sojourns resonate with and mirror the 'Unity of Being' where two things, although identical, are distinguishable from one another; so that in one sense, the one is the other, while in another sense, it is not (Affifi 1998: 12). Such ideas invite a deeper understanding and interpretation of PBS and of its relation to the paradoxical ideas around consciousness, aesthetic encounter, technological mediation and transcendence.

Coming back to earth, it can be said that regardless of format, context or specific content, all park bench sojourns serve the same end: to provide a bench-based aesthetically reflexive moment-in-time. At its simplest, the project is about awareness. In detail, sojourns augment experience in ways that combine and contrast the present-and-embodied with the absent-andvirtual. Beyond the technical needs of translating PBS into a VR experience (see below), the VR dimension complements the conceptual basis and related experiences of PBS in interesting ways.

To translate PBS into VR a bench in an open field within a forest-like environment was simulated (Figure 1). The bench was both physically and virtually present, with an accurate VR version of the physical bench rendered in VR and positioned to match the participant's physical/virtual spatial fields. In the middle distance in front of the seated participant was a 'pop-up' video screen upon which played a sequence of videos shot from other park benches (taken from the PBS project archives). Through headphones the participant heard stereo park bench audio recordings played in a smoothly layered sequence (also taken from the PBS archives they were chosen for their correspondence with the simulated visual space to aid a 'sense of presence'). The artistic 
intent was to activate the juxtaposition characteristic of the project, a 'there' but'not there', a'same' but 'not same', shared realities across present-embodied / absent-virtual. An intriguing addition brought by the VR context was the double layering and hierarchizing of these relations. Place illusion (Slater and Sanchez-Vives 2016) was necessary for the VR-based sojourn to effectively take place. Within the VR space, with place illusion and presence established, the sojourn juxtaposed this already and over-arching technologically mediated park bench experience (the VR environment itself) with views and, to a less extent, audio from other park benches. These layered complexities, combined with research suggesting that in VR bodily awareness can become transformed (e.g. failing to feel one's body, loss of perception of body boundaries, absence of a sense of gravity, etc., see Murray and Gordon 2001; Murray and Sixsmith 1999) provide additional experiential qualities that help extend the scope of PBS' artistic exploration of paradoxical, yet commonplace, conflations of experience, perception, consciousness and being.

At the levels of design, intention and participant experience there are some parallels between PBS and research into VR and mindfulness. In mindfulness research, VR environments have been used to help focus attention to facilitate mindfulness training (see Navarro-Haro et al. 2017; Seabrook et al. 2020). In such research and PBS there is a shared intention to direct consciousness towards the present moment without attachment or judgement, and with curiosity, openness and acceptance (Navarro-Haro et al. 2017: 2). For PBS an artistic aesthetical and conceptual agenda is employed, whereas in mindfulness VR, clinical and therapeutic agendas lead. PBS is an experimental and performative artwork that invites participants into an active and questioning space that is open to multiple and individual outcomes; mindfulness VR experiences, by contrast, are typically directed, often including voice-over prompts from a guiding clinician, towards achieving a specifically framed type of consciousness (i.e.'aware' and 'mindful').

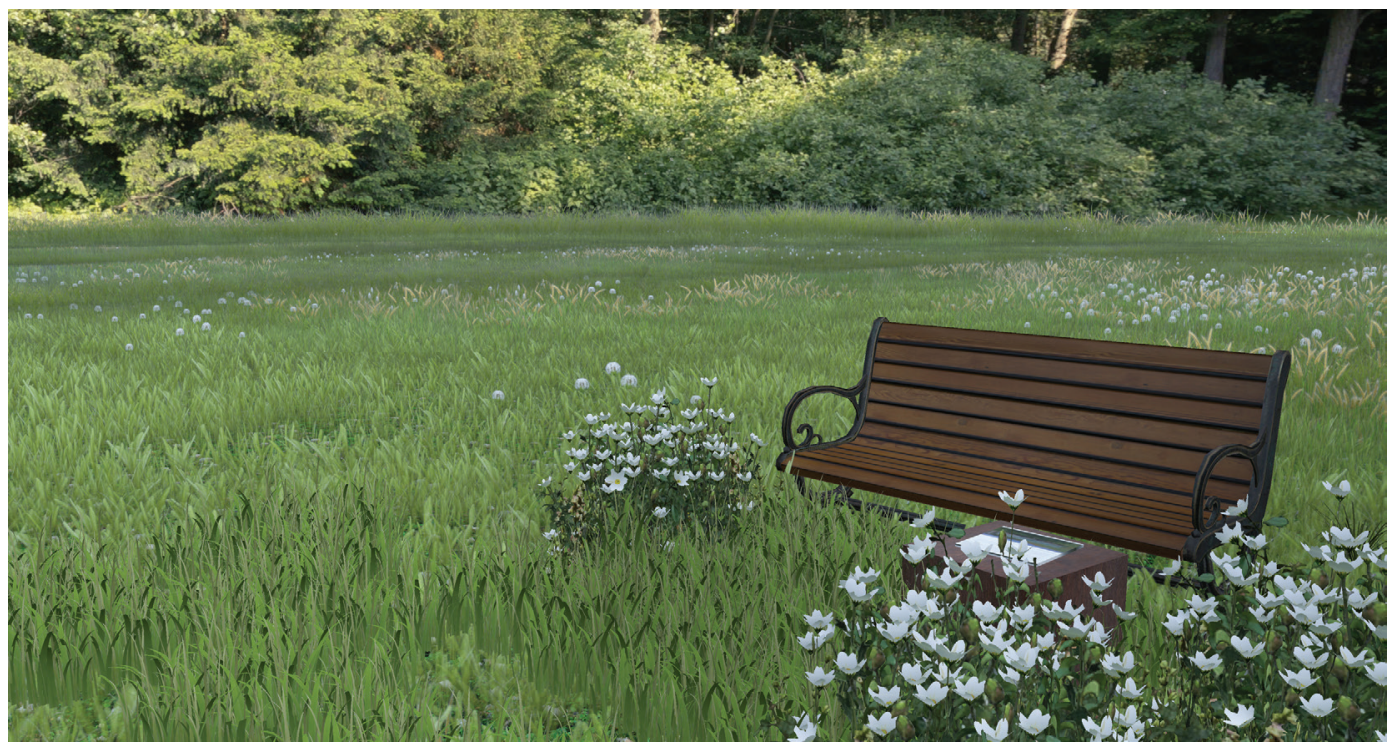

Figure 1: Park Bench Sojourn virtual reality environment. 


\section{VIRTUAL REALITY AND SONIC IMPLEMENTATION}

The Park Bench Sojourn VR environment was created combining spherical panorama and 3D computer graphics elements. Figure 1 shows where participants could immerse themselves in this VR environment using widely available Steam VR-enabled head-mount-devices (HMD) with an optimum display with approximately 2880x1600 (1440x1600 per eye) resolution. Currently, there are more than ten VR headsets available off-the-shelf that are compatible with such content. Figure 2 shows users experiencing the VR content and the 'pop-up' video screen referred to earlier. To aid in establishing presence, dynamic elements such as foliage, particles, tiny insects, and wind were rendered randomly to provide participants with a more 'natural' non-repeating experience.

Moving forward, a logical and relatively simple next step would be to incorporate 3D spatial audio and object-based sonic programming to improve the VR user experience. In terms of 3D modelling, we are experimenting with high-fidelity VR nature content creation. As shown in Figure 3, this demonstrates a forest with a large amount of highly detailed foliage and nature-based elements populated using an AI-assisted procedural approach working in combination with hyper-realistic photogrammetric 3D content. Furthermore, nature-based content can be configured with components placed randomly to enhance its perception as genuinely natural; also, highly detailed 3D scanned photogrammetry components, including rocks, bark and tree trunks, can be added to mimic the natural elements of the physical world. This workin-progress, as shown in Figure 3 (image courtesy of the multi-disciplinary collaboration of Altered Memories, Moves like Sunlight, SafeSpace VR), has been tested using a 24-hour realistic day-night cycle. Designers can manually determine the time of the day, and alter, for example, sunlight intensity to control shadows (soft or hard) and variations in colour temperature. Highfidelity VR experience is, however, still at an early stage of the development. It also requires high-calibre computing power to render such levels of content complexity and to operate the supporting hardware. To illustrate, a newer PBS prototype intended to work with 4320x2160 (2160x2160 per eye) resolution requires a 'temporal anti-aliasing' computer rendering technique to work properly to reduce pixilation in the VR display and requires VR-enabled workstations with a high-speed Graphics Processing Unit.

More broadly, future implementations of PBS VR might explore $360^{\circ}$ video as an alternative to 3D modelling (as in Seabrook et al. 2020); bodilyVR representation (hands and forearms to full body); mobility to different benches within a single scene or to other scenes; user interaction to determine aspects of the sojourn, or sojourns, taken (drawn from the PBS archive as well as from otherVR-specific sojourns that might be developed).
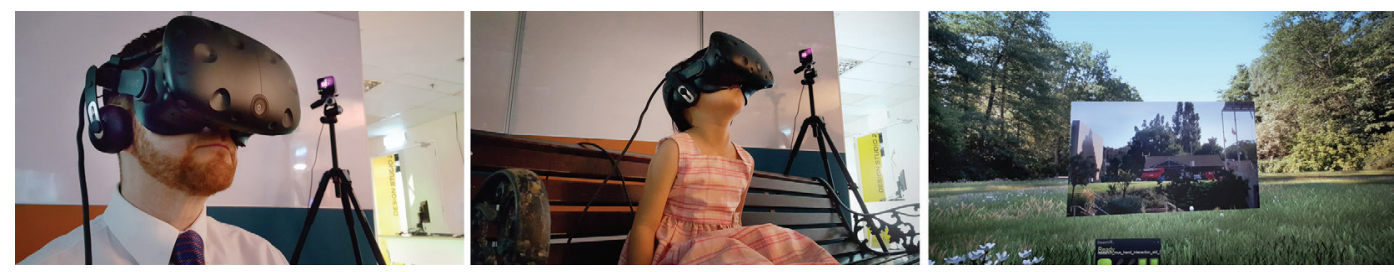

Figure 2: VR user experience. 


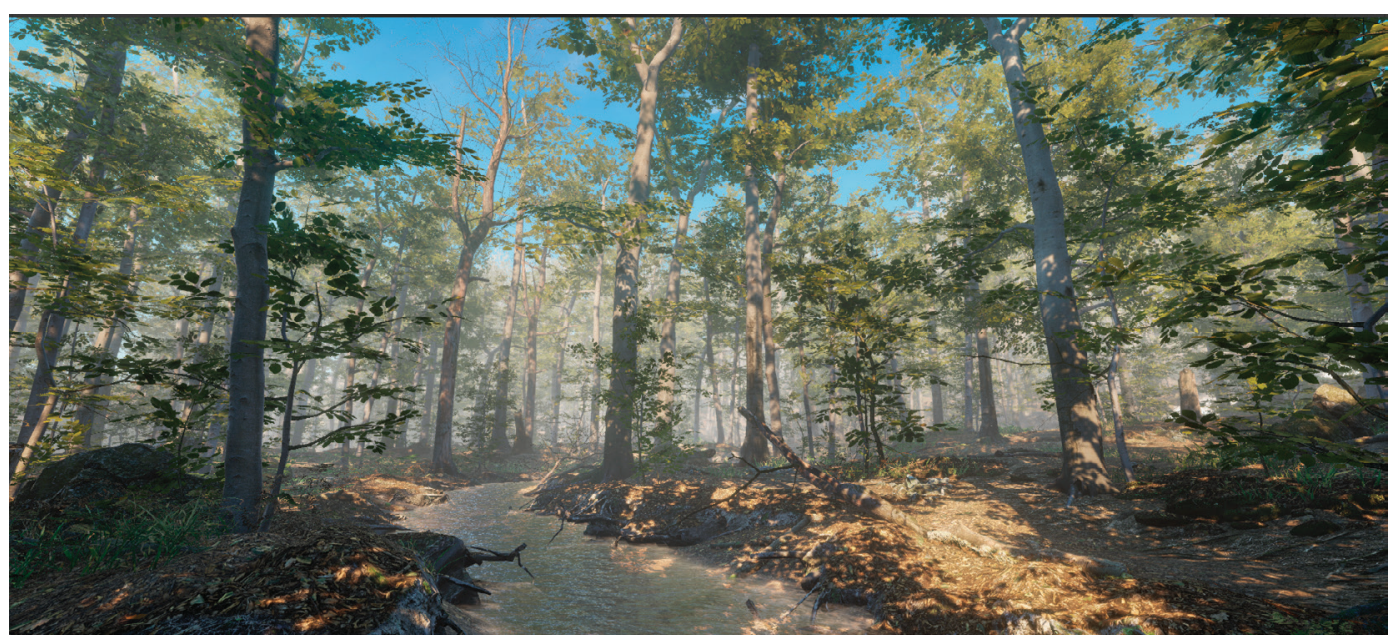

Figure 3: High-fidelity realistic VR content creation and prototyping.

\section{FUTURE DIRECTIONS}

Because of the artistic origins of the project, user experience data is anecdotal and based only on informal conversations with participants or gathered from the authors' colleagues and friends; future work would rectify this. Even though from an arts' perspective this might arguably be atypical, it would be a necessary means of expanding the scope and claims of the work's efficacy and understanding its potential for other applications. It would also help determine how this project might be of benefit to the social good.

As has been discussed, PBS VR, like other VR environments, provides an immersive experience to replicate physical environments digitally such that a 'sense of presence' is established for practical VR user experience (Morie 2007; Sherman and Craig 2003). It has been shown that extended reality technologies can be useful in aiding knowledge-based demonstrations and educational VR experiences (Marsh and Costello 2012; Domingo et al. 2018; Horst and Dorner 2018; Dey et al. 2018). PBS VR has the potential for development as part of environmental education, engagement and awareness strategies. VR applications have also been explored in a variety of therapeutic contexts. In addition to mindfulness training already referred to, studies have shown that VR has been used for managing the well-being of dementia patients (Rose et al. 2018). Guillén et al. (2018) have also highlighted the possibilities and importance of customizable VR content for enhancing stress-management therapy with positive usability results and feedback from participants. VR research focusing on restorative and relaxation applications (Blum et al. 2019; Valtchanov et al. 2010; Roche et al. 2019) has also shown useful and positive findings in improving mental wellness, especially in the context of physical illness or disability. PBS VR has significant potential across a number of these areas. The original intention for PBS VR was accessibility driven, with the idea to cater for people who were immobile and unable to take physical sojourns. This included the idea of bespoke $360^{\circ}$ video sojourns to park benches long loved by a particular individual, and that through the experience they would be able to revisit this specific place and share the experience with others. This is one example of how PBSVR might extend its artistic base towards elder care 
encompassing emotional and mental well-being. In collaboration with social care partners, other possibilities that are more practical and wide-reaching could be developed.

One final area to mention relates to remaining and developing PBS VR within the arena of arts-practice combined with human-computer-interaction research. PBS VR has at its heart a disruptive intent to deliver a VR experience that counters VR's stereotypical emphasis on stimulation and interactivity. To subvert technologies through misuse and misappropriation is a well-established artistic trope, and PBS VR is intended as a gesture in this direction. Exploiting the way VR adds another layer to the project's layering of benchbased experiences and subject positions is part of this, as is the playful surreality of the 'pop-up' video screen in the middle of a field. There is certainly more that can be done in this vein; PBS VR does little to critique the actual mechanisms and basis for 'successful'VR experiences. Further work here might, for example, disrupt the 'sense of presence' to aggravate and conflict perceived notions of consciousness or body presence to artistic ends. On the other hand, and more in keeping with PBSVR's current direction, and remembering Harold Budd, who sadly died this December, it could be that a more explicitly ambient and aesthetic form of PBS VR might be developed. The emphasis here would be upon ways in which artistic experiences contribute to the social good through the therapeutic potential of aesthetically rooted calming experiences. PBS VR as a base could lead to numerous realizations of such a goal, and in the process broaden the scope of VR experience by exploring and extending the role of sound, music, vision and other senses in VR.

\section{REFERENCES}

Affifi, Abul Ela (1998), The Twenty-Nine Pages: An Introduction to Ibn'Arabi's Metaphysics of Unity, Cirencester: Beshara Publications.

Bernard, Rhoda (2009), 'Music making, transcendence, flow, and music education', International Journal of Education and the Arts, 10:14, pp. 1-21.

Blum, Johannes, Rockstroh, Christoph and Göritz, Anja S. (2019), 'Heart rate variability biofeedback based on slow-paced breathing with immersive virtual reality nature scenery', Frontiers in Psychology, 10:2172, https:// www.frontiersin.org/articles/10.3389/fpsyg.2019.02172/full. Accessed 15 December 2020.

Bogden, Deanne (2010), 'The Shiver-Shimmer factor: Musical spirituality, emotion, and education', Philosophy of Music Education Review, 18:2, pp. 111-29.

Bolt, Barbara (2010), Art Beyond Representation: The Performative Power of the Image, London: I.B. Tauris.

Borgdorff, Henk (2010), 'The production of knowledge in artistic research', in M. Biggs and H. Karlsson (eds), The Routledge Companion to Research in the Arts, London: Routledge, pp. 44-63.

Borgo, David (2005), Sync or Swarm, New York: Continuum.

Boyce-Tillman, June (2007), 'Spirituality in the musical experience', in L. Bresler (ed.), International Handbook of Research in Arts Education, London: Springer, pp. 1405-24.

Crouch, David (2012), 'Landscape, performance and performativity', in P. Howard, I. Thompson and E. Waterton (eds), The Routledge Companion to Landscape Studies, London: Routledge, pp. 119-28. 
Dey, Arindam, Billinghurst, Mark, Lindeman, Robert W. and Swan II, J. Edward (2018), 'A systematic review of 10 years of augmented reality usability studies: 2005 to 2014', Frontiers in Robotics and AI, 5:37, https://www.frontiersin.org/articles/10.3389/frobt.2018.00037/full. Accessed 15 December 2020.

Domingo, Jelia R., and Bradley, Elizabeth Gates (2018), 'Education student perceptions of virtual reality as a learning tool', Journal of Educational Technology Systems, 46:3, pp. 329-42.

Guillén, Verónica, Baños, Rosa M. and Botella, Cristina (2018), 'Users' opinion about a virtual reality system as an adjunct to psychological treatment for stress-related disorders: A quantitative and qualitative mixed-methods study', Frontiers in Psychology, 9:1038, https://www.frontiersin.org/articles/10.3389/fpsyg.2018.01038/full. Accessed 15 December 2020.

Haseman, Brian (2006), 'A manifesto for performative research: Media international Australia incorporating culture and policy', Practice-led Research, 118, pp. 98-106.

Haseman, Brian (2010), 'Rupture and recognition: Identifying the performative research paradigm', in B. Bolt and E. Barrett (eds), Practice as Research: Approaches to Creative Arts Enquiry, London: I.B. Tauris, pp. 147-58.

Hogg, Bennett (2013), 'The violin, the river, and me: Artistic re-search and environmental epistemology in balancing string and devil's water 1, two recent environmental sound art projects', Hz-Journal, 18, http://www. hz-journal.org/n18/hogg.html. Accessed 15 December 2020.

Hogg, Bennett (2020), 'Landscape quartet: Creative practice and philosophical reflexion in natural environments', UK Research Councils, https://gtr.ukri. org/projects?ref=AH\%2FJ004995\%2F1. Accessed 15 December 2020.

Horst, Robin and Dörner, Ralf (2018), 'Opportunities for Virtual and Mixed Reality Knowledge Demonstration', 2018 IEEE International Symposium on Mixed and Augmented Reality Adjunct (ISMAR-Adjunct), Munich, Germany, 2018, pp. 381-85, https://doi.org/10.1109/ISMAR-Adjunct.2018.00110. Accessed 11 May 2021.

Ingold, Tim (2000), The Perception of the Environment, London: Routledge.

Marsh, Tim and Costello, Brigid M. (2012), 'Experience in serious games: Between positive and serious experience', Proceedings of the Third international conference on Serious Games Development and Applications, https://doi. org/10.1007/978-3-642-33687-4_22. Accessed 15 December 2020.

Morie, Jacquelyn Ford (2007), 'Performing in (virtual) spaces: Embodiment and being in virtual environments', International Journal of Performance Arts and Digital Media, 3:2\&3, pp. 123-38.

Murray, Craig D. and Gordon, Michael S. (2001),'Changes in bodily awareness induced by immersive virtual reality', CyberPsychology \& Behavior, 4:3, pp. 365-71.

Murray, Craig D. and Sixsmith, Judith (1999), 'The corporeal body in virtual reality', Ethos, 27: 3, pp. 315-43.

Nachmanovitch, Stephen (1990), Free Play: Improvisation in Life and Art, New York: Tarcher/Penguin.

Navarro-Haro, Marivi V., López-del-Hoyo, Yolanda, Campos, Daniel, Linehan, Marsha M., Hoffman, Hunter G., García-Palacios, Azucena, ModregoAlarcón, Marta, Luis Borao, Luis and García-Campayo, Javier (2017), 'Meditation experts try virtual reality mindfulness: A pilot study evaluation of the feasibility and acceptability of virtual reality to facilitate mindfulness practice in people attending a mindfulness conference', PLOS ONE, 12:11, p. e0187777. 
Nelson, James M. (2009), Psychology, Religion, and Spirituality, New York: Springer.

Roche, Kayla, Liu, Stephen and Siegel, Steven (2019), 'The effects of virtual reality on mental wellness: A literature review', Journal of Neurology, Psychiatry and Brain Research, 2019:01, pp. 1-8.

Rooth, Graham (2008), Prophet for a Dark Age: A Companion to the Works of René Guénon, Brighton: Sussex Academic Press.

Rose, Vienna, Stewart, Inga, Jenkins, Keith G., and Ang, Chee Siang and Matsangidou, Maria (2018), 'A scoping review exploring the feasibility of virtual reality technology use with individuals living with dementia', in G. Bruder, S. Cobb and S. Yoshimoto (eds), International Conference on Artificial Reality and Telexistence, Limassol, 7-9 November, Eurographics Symposium on Virtual Environments 2018, ICAT-EGVE, https://diglib.eg.org/ handle/10.2312/egve20181325. Accessed 15 December 2020.

Sansom, Matthew (2015), 'Dissolving dualities: Onto-epistemological implications of ecological sound art', Contemporary Music Review, 34:4, pp. 267-80.

Sansom, Matthew (2017), 'Under the aspect of eternity: A perennialist interpretation of free improvisational aesthetics and pedagogy', in J. BoyceTillman (ed.), Spirituality in Music Education, Oxford: Peter Lang, pp. 67-86.

Sansom, Matthew (2020), 'Home page', Park Bench Sojourn, http://www.parkbenchsojourn.org. Accessed 15 December 2020.

Seabrook, Elizabeth, Kelly, Ryan, Foley, Fiona, Theiler, Stephen, Thomas, Neil, Wadley, Greg and Nedeljkovic, Maja (2020), 'Understanding how virtual reality can support mindfulness practice: Mixed methods study', Journal of Medical Internet Research, 22:3, p. e16106.

Sherman, William R. and Craig, Alan B. (2003), Understanding Virtual Reality, Morgan Kaufman Publishers, Elsevier Science.

Slater, Mel and Sanchez-Vives, Maria V. (2016), 'Enhancing our lives with immersive virtual reality', Frontiers in Robotics and AI, 3:74, https://doi. org/10.3389/frobt.2016.00074. Accessed 15 December 2020.

Valtchanov, Deltcho, Barton, Kevin R. and Ellard, Colin (2010), 'Restorative effects of virtual nature settings', Cyberpsychology, Behavior, and Social Networking, 13:5, https://doi.org/10.1089/cyber.2009.0308. Accessed 15 December 2020.

Vogel, Sabine (2015), 'Tuning-in', Contemporary Music Review, 34:4, pp. 327-34. Waterton, Emma (2012), 'Landscape and non-representational theories', in P. Howard, I. Thompson and E. Waterton (eds), The Routledge Companion to Landscape Studies, London: Routledge, pp. 66-75.

\section{SUGGESTED CITATION}

Sansom, Matthew and See, Zi Siang (2021), 'Translating performative mediated art into virtual reality: A case study', Virtual Creativity, 11:1, pp. 53-65, https://doi.org/10.1386/vcr_00042_1

\section{CONTRIBUTOR DETAILS}

Matthew Sansom is an artist working across a variety of media and contexts including sound, video, sculpture, installation, performance and musical composition. His work has been exhibited and performed internationally, including the National Theatre of Prague, Victoria \& Albert Museum, ICA (London), CCA (Glasgow), t-u-b-e galerie (Munich), Korean Institute of 
Culture and Ely Cathedral. Commissions have included sound-based works for Liverpool City Council, Huddersfield Contemporary Music Festival and the Four Seasons Hotel, Shanghai. He holds a doctorate in musicology/music psychology on the topic of free improvisation and has research interests in the philosophy, aesthetics and pedagogy of creative process. After twenty years in the United Kingdom at the Universities of Newcastle and Surrey, he is now professor of music and PVC-education at Sunway University, KL, Malaysia.

Contact: Sunway University, Centre for Research-Creation in Digital Media, 5, Jalan Universiti, Bandar Sunway, 47500 Petaling Jaya, Selangor, Malaysia.

E-mail: msansom@sunway.edu.my

(D) https://orcid.org/0000-0003-3322-8127

Dr Zi Siang See has specialized over the past ten years in the design, use and integration of interactive media, including but not limited to augmented reality (AR) and virtual reality (VR) research-creation. Zi has over fifteen years' experience of working within the field of interaction design and digital media in both industry and within university institutions, nationally and internationally. As an early career researcher, he has been part of various MOOC projects and been actively involved in scholarly research and international collaborations. His work has contributed to new systems, theory and studies in human-computer-interaction, education technologies and inclusive design. Some of these technical research articles were published at specialized venues such as SIGGRAPH, IEEE Virtual Systems and Multimedia (VSMM) and the Springer's Virtual Reality. Zi is also working on extended reality $(\mathrm{XR})$ research projects in digital heritage, medical and health sciences training.

Contact: University of Newcastle, School of Creative Industries, University Dr, Callaghan, NSW 2308, Australia.

E-mail: zisiang.see@newcastle.edu.au

(1) https://orcid.org/0000-0002-6079-176X

Matthew Sansom and Zi Siang See have asserted their right under the Copyright, Designs and Patents Act, 1988, to be identified as the author of this work in the format that was submitted to Intellect Ltd. 